\title{
HONORÉ DE BALZAC, Il figlio maledetto
}

\section{Marco Stupazzoni}

\section{OpenEdition \\ Journals}

\section{Edizione digitale}

URL: https://journals.openedition.org/studifrancesi/45229

DOI: 10.4000/studifrancesi.45229

ISSN: 2421-5856

\section{Editore}

Rosenberg \& Sellier

\section{Edizione cartacea}

Data di pubblicazione: 1 août 2021

Paginazione: 385

ISSN: 0039-2944

\section{Notizia bibliografica digitale}

Marco Stupazzoni, «Honoré de BALZAc, I/ figlio maledetto», Studi Francesi [Online], 194 (LXV | II) | 2021, online dal 01 septembre 2021, consultato il 15 octobre 2022. URL: http://journals.openedition.org/ studifrancesi/45229; DOI: https://doi.org/10.4000/studifrancesi.45229

Questo documento è stato generato automaticamente il 15 octobre 2022.

\section{(c) (i) ()}

Creative Commons - Attribuzione - Non commerciale - Non opere derivate 4.0 Internazionale - CC BYNC-ND 4.0

https://creativecommons.org/licenses/by-nc-nd/4.0/ 


\title{
HONORÉ DE BALZAC, Il figlio maledetto
}

\author{
Marco Stupazzoni
}

\section{NOTIZIA}

HONORÉ DE BALZAC, Il figlio maledetto, introduzione di A. Ginzburg, traduzione di M.

Bertini, con testo a fronte, Venezia, Marsilio, 2019, «Letteratura universale Marsilio», $292 \mathrm{pp}$.

1 Composto in diversi momenti tra il 1831 e il 1836, L'Enfant maudit di Balzac trova la sua definitiva e meritata consacrazione in Italia grazie a questa pregevole edizione bilingue del racconto esemplarmente tradotto da Mariolina Bertini e magistralmente presentato da Alessandra Ginzburg. A confronto con i più noti e celebrati romanzi filosofici balzachiani, L'Enfant maudit contiene una sorprendente concentrazione di temi importanti che toccano, illustrano e ricompongono le idee fondanti e le sfumature più originali del pensiero di Balzac per quel che riguarda la concezione dell'individuo visto nelle sue relazioni di immanenza e di trascendenza rispetto alla natura, alla realtà e a Dio.

2 Pur considerando i diversi significati e la molteplicità dei livelli interpretativi peculiari ai diversi testi delle Études philosophiques, l'idea centrale che permea e che attraversa l'intero corpus di questi studi è senza dubbio quella del «pensiero che uccide»: un pensiero a cui corrisponde una intensità «potenzialmente infinita» (p.15) delle emozioni, e che determina nell'individuo la consunzione irreversibile della propria energia vitale. Sono proprio le intuizioni balzachiane sulla «incommensurabilità del mondo emotivo» a costituire l'aspetto sorprendentemente moderno di questo testo. La lettura che Alessandra Ginzburg offre del Figlio maledetto ci consente di interpretare il racconto non soltanto come «la manifestazione del pensiero dell'emozione che uccide», ma più ancora come «la descrizione esemplare di un universo emotivo conchiuso in sé stesso in cui la forza esplosiva della simmetrizzazione regna sovrana nella dimensione delle relazioni affettive» (p. 17). 
3 Condannato dalla crudeltà tanto delle leggi biologiche quanto delle leggi sociali a un destino di solitudine e di sofferenza, Étienne, il figlio maledetto ripudiato dal padre, ritaglia la propria esistenza sulla necessità di vivere protetto da stimoli troppo violenti. I suoi rapporti sociali si limitano alle esperienze di rifiuto, di dolore e di morte condivise con la madre alle quali farà seguito la scelta (forzata) dell'esilio in una intensa comunione con la natura. Nell'Oceano, Étienne ritroverà quel legame profondo ed estinto con la madre e ne sentirà ovunque la presenza e la voce. Questa «omologazione inconscia fra l'infinita distesa marina e l'amore infinito proveniente dalla figura materna avviene con naturalezza» (p. 28) e consentirà ad Étienne di unirsi alla natura e di comprenderne i misteri. Con l'apparizione di Gabrielle, «il cerchio delle identificazioni simmetriche si chiude» (p. 32). Come Étienne, Gabrielle mostra i tratti e le qualità che caratterizzano, in Balzac, le creature angeliche: nella loro unione, anima e corpo si trovano congiunti in una specie di sostanza unica che forma l'essere angelizzato e che ingloba, in un continuum mistico di tensione trascendente, anche la figura della madre. Non solo, quindi, Gabrielle è, per Étienne, la madre, «ma lui stesso può, identificandosi con lei, amare così come è stato amato [...]. L'amore materno è al momento l'unico modello amoroso che Étienne conosca: i suoi due affetti sono sempre riuniti in modo tale da non entrare mai in conflitto. [...] Insieme realizzano il sogno di Platone: sono un solo essere divinizzato. È l'infanzia di un piacere che ancora non si conosce, che riscopre l'eterno linguaggio dell'amore» (p. 34). 